16. Гросс К.Ю. Материалы по меловой флоре Саратовской губернии: Crambe Litwinowi Gross. Катран приволжский // Известия Саратовского о-ва естествоиспытателей. Саратов, 1928. Т. ІІ, вып. 2. С. 105-108.

17. Спрыгина Л.И. Иван Иванович Спрыгин (1873-1942). M., $1982.176 \mathrm{c}$.

18. ГАСО. Ф.1166, оп.1, ед. хр. № 252, лл. 16.

19. Там же. Ф.521, оп.1, ед. хр. № 752, лл. 164.

20. Там же. Ф.2650, оп.1, ед. хр. № 615, лл. 26-28.

21. Рубанов М.Н. Особо ценные лесные насаждения // Природа и люди. Саратов, 1976. С. 145-150.

22. Миловидова И.Б. Дендрологические редкости // Там же. С. $159-169$.

23. Девишев Р.А., Чекрыгина В.С., Свириденко В.Т. Достопримечательности живой природы // Природа родного края и её охрана. Саратов, 1971. С. 232-246.

24. Будигина Л.В. Охрана памятников природы Саратовской области // Вопросы истории и теории физической географии. Саратов, 1979. Вып. 5(12). С. 81-100.

25. Фурсаев А.Д. Объекты растительного покрова Саратовской области, подлежащие охране // Охрана природы и озеленение населенных пунктов: Материалы VI Bceуральского совещания по вопросам географии и охраны природы. Уфа, 1961. С. 71-76.

26. Алексеевская Н.К., Добрина Н.Д., Макаров В.3. История развития кафедры физической географии и ландшафтной экологии // Развитие физической географии и ландшафтной экологии в Саратовском университете / Под ред. д-ра геогр. наук, проф. В.З. Макарова. Саратов, 2005. C. 6-26.

27. Кох E.К. Охрана флоры и растительности Саратовской области // Экологические и фитоценотические исследования на Юго-Востоке Европейской части СССР. Саратов, 1973. C. 89-94.

28. Будигина Л.В. Типичные ландшафты - под охрану // Природа и люди. Саратов, 1976. С. 223-227.

УДК $913(470.44)+002: 001+577.4$

\section{НЕКОТОРЫЕ РЕЗУЛЬТАТЫ ЛАНДШАФТНО-ЭКОЛОГИЧЕСКИХ ИССЛЕДОВАНИЙ НА ТЕРРИТОРИИ ХВАЛЫНСКОГО НАЦИОНАЛЬНОГО ПАРКА}

\author{
В.3. Макаров, А.Н. Чумаченко', В.А. Данилов, \\ Ю.В. Волков, А.В. Федоров 1
}

Саратовский государственный университет, кафедра физической географии и ландшафтной экологии, 1 кафедра геоморфологии и геоэкологии E-mail: urbolab@sgu.ru

В статье изложены современные проблемы организации научной работы в Хвалынском национальном парке. Рассмотрена программа ландшафтно-экологических исследований в Парке. Приводятся некоторые результаты ландшафтно-геохимических работ и снегомерной съемки в центральной части Парка. Изучаются перспективы дальнейших исследований с применением ГИС-технологий.
29. ГАСО. Ф. 1738, оп. 8-пр., ед. хр. № 1963, лл. 137-146. Об утверждении перечня памятников природы местного значения: Решение Саратовского облисполкома от 15.07.82 г. № 342 .

30. Там же. Ед. хр. № 3177, лл. 125-152. Об утверждении перечня государственных памятников природы: Решение Саратовского облисполкома от 27.12.91 г. № 328 .

31. Об утверждении Перечня памятников природы регионального значения в Саратовской области: Постановление губернатора Саратовской области от 21.04.97 г. № 321 // СПС «КонсультантПлюс».

32. Места заповедные: Сб. очерков / Ред., сост. Л.А. Розанова. Саратов, $1981.79 \mathrm{c}$.

33. Никитина О.В. За голубым тюльпаном: Сб. очерков. Саратов, 1989. $120 \mathrm{c}$.

34. Опасайтесь потерять друзей: Очерки об охране природы Саратовской области. Саратов, 1983. $112 \mathrm{c}$.

35. Чигуряева А.А., Лебедев В.А., Миловидова И.Б., Мичурин В.Г. Подлежащие охране ботанические объекты Саратовской области // Вопросы ботаники Юго-Востока. Саратов, 1988. С. 3-30.

36. ГАСО. Ф. 1738 , оп. 8-пр., ед. хр. № 2453 , лл. 6.

37. Там же. Ед. хр. № 3010, лл. 50-52.

38. Там же. Ед. хр. № 3027, лл. 57-62.

39. Будигина Л.В. Объекты редкие и ценные: памятники природы // Коммунист (Саратов). 1984. 20 апр. № 91, 4 с.

40. ГАСО. Ф. 1738, оп. 8-пр., ед. хр. № 2628, лл. 98.

41. Там же. Оп. 2, ед. хр. № 2208, лл. 11-15.

42. Состояние окружающей среды и природных ресурсов Саратовской области в 2000 г. Саратов, 2001. 160 с.

43. Доклад о состоянии и об охране окружающей среды Саратовской области в 2004 г. Саратов, 2005. 158 с.

44. Волков Ю.В. Сеть особо охраняемых природных территорий Саратовской области в ландшафтной структуре региона // Изв. Сарат. ун-та. Новая серия. 2004. Т. 4, вып. 1-2. C. $167-174$.
Some Results of Landscape-ecological Researches on Territory Hvalynsky National Park

\section{V.Z. Makarov, A.N. Chumachenko, V.A. Danilov, Yu.V. Volkov, A.V. Fedorov}

In article modern problems of the organization of scientific work in Hvalynsky national park are stated. The program of landscapeecological researches in Park is considered. Some results of landscapegeochemical works and snow shootings in the central part of Park are proofs. Prospects of the further researches with application of GIS-technologies are studed. 


\section{Постановка проблемы}

Хвалынский национальный парк - единственный национальный парк в Нижнем Поволжье. Основанный в 1994 г. на базе Хвалынского лесхоза, Парк до сих пор испытывает трудности с научным обеспечением своей деятельности. Основные задачи национальных парков как особого типа охраняемых природных территорий - сохранение типичных и уникальных природных геосистем в сочетании с организацией природощадящего (экологического) туризма и отдыха на природе. Иными словами, национальный парк сочетает функции заповедника и рекреационной территории. По опыту работы национальных парков Северной Америки видно, что подобное сочетание дает экономическую эффективность.

К сожалению, в Хвалынском парке опыт научно обоснованной природоохранной работы находится в начальной стадии. Причем природоохранная деятельность связана в основном с практической работой по лесовосстановлению на безлесных эродированных территориях, санитарными выборочными рубками и обеспечением противопожарной безопасности.

Собственно научная работа выполняется на безвозмездной основе сотрудниками и студентами биологического и географического факультетов Саратовского госуниверситета и частично Саратовского аграрного университета.

В статье приводятся некоторые результаты комплексных ландшафтно-экологических исследований преподавателей, аспирантов и студентов географического факультета Саратовского государственного университета в 2002-2005 годах.*

\section{Основные цели и задачи ландшафтно-экологических исследований в Хвалынском национальном парке и буферной зоне. Организация и содержание работ в предполевой и полевой этапы}

Прежде чем приступить к собственно полевым работам на территории Парка, была разработана научная программа ландшафтно-экологических исследований, были определены их цели и задачи. Основные положения научной программы изложены в статье В.З. Макарова и В.А. Данилова «Волжская “Швейцария” - Хвалынский национальный парк: природные особенности и проблемы развития» [1]. Здесь же отметим, что в настоящее время выполнен значительный объем камеральной работы для научного обеспечения полевых исследований.

1. Создана базовая цифровая карта территории Парка в масштабе $1: 25000$. Карта выполнена в векторном формате и имеет открытое содержание. Она содержит десятки тематических слоев,

\footnotetext{
* В разные годы в сборе и обработке полевого материала участвовали Н.В. Пичугина, Л.А. Тархова, А.Н. Павлова, М.В. Елаева, Д.В. Кривцов, студенты 3-4 курсов географического факультета. Всем им авторы выражают глубокую благодарность.
}

присущих топографической карте указанного масштаба. Кроме того, выполнены цифровые векторные карты территории Парка, буферной (охранной) зоны и Хвалынского района в масштабах $1: 100000$ и $1: 200000$. Речь идет об общегеографических, топографических картах, позволяющих строить специализированные тематические карты и математико-картографические модели.

2. Проанализирован, обобщен и переведен в электронную форму материал по последней лесотаксации территории бывшего Хвалынского лесхоза, а ныне Национального парка, за 1994 г., что позволяет оперативно строить разнообразные тематические карты по материалам лесоустройства [2].

3. Приобретены, трансформированы и привязаны к базовой цифровой карте территории Парка космоснимки высокого разрешения. Создана космофотокарта Хвалынского национального парка и его буферной территории.

4. На основе базовых карт построена цифровая модель рельефа центрального участка Парка и разнообразные морфометрические карты (углов наклона земной поверхности, экспозиции склонов, эрозионной расчлененности и др.).

5. Определены и нанесены на базовую цифровую карту масштаба $1: 25000$ границы и линии полигонов-трансект и местоположения модельных площадок полевых ландшафтно-экологических исследований. Разработана форма полевого бланка описания структуры и состояния модельных биогеоценозов.

6. Подготовлены разнообразные атрибутивные базы данных об истории создания и процессе формирования Хвалынского природного парка как природоохранного и рекреационного учреждения.

Полевые работы в Парке начались летом 2002 г. и были продолжены в последующие годы. В них приняли участие студенты, аспиранты и преподаватели географического факультета. На заранее определенных участках исследовательских полигонов-трансект было заложено 45 площадок комплексного изучения доминантных, субдоминантных и эпизодических фаций (рисунок).

Ландшафтно-экологические исследования проводились по единой программе [3, 4], включая рекогносцировочные и основные маршрутные и полустационарные исследования на 10 полигонах-трансектах с отбором проб почвы и воды из ручьев, речек и прудов, микроклиматическими наблюдениями, выявлением визуальных бассейнов и оценкой уровней пасквальной и рекреационной дигрессии, других видов хозяйственной нагрузки. Всего было обработано около 200 почвенных проб из разных генетических горизонтов почвы на 81 площадке почвенного опробования.

Почвенные образцы были взяты из шурфов, сделанных в разных элементарных геохимических ландшафтах и различных функциональных зонах территории Парка. 


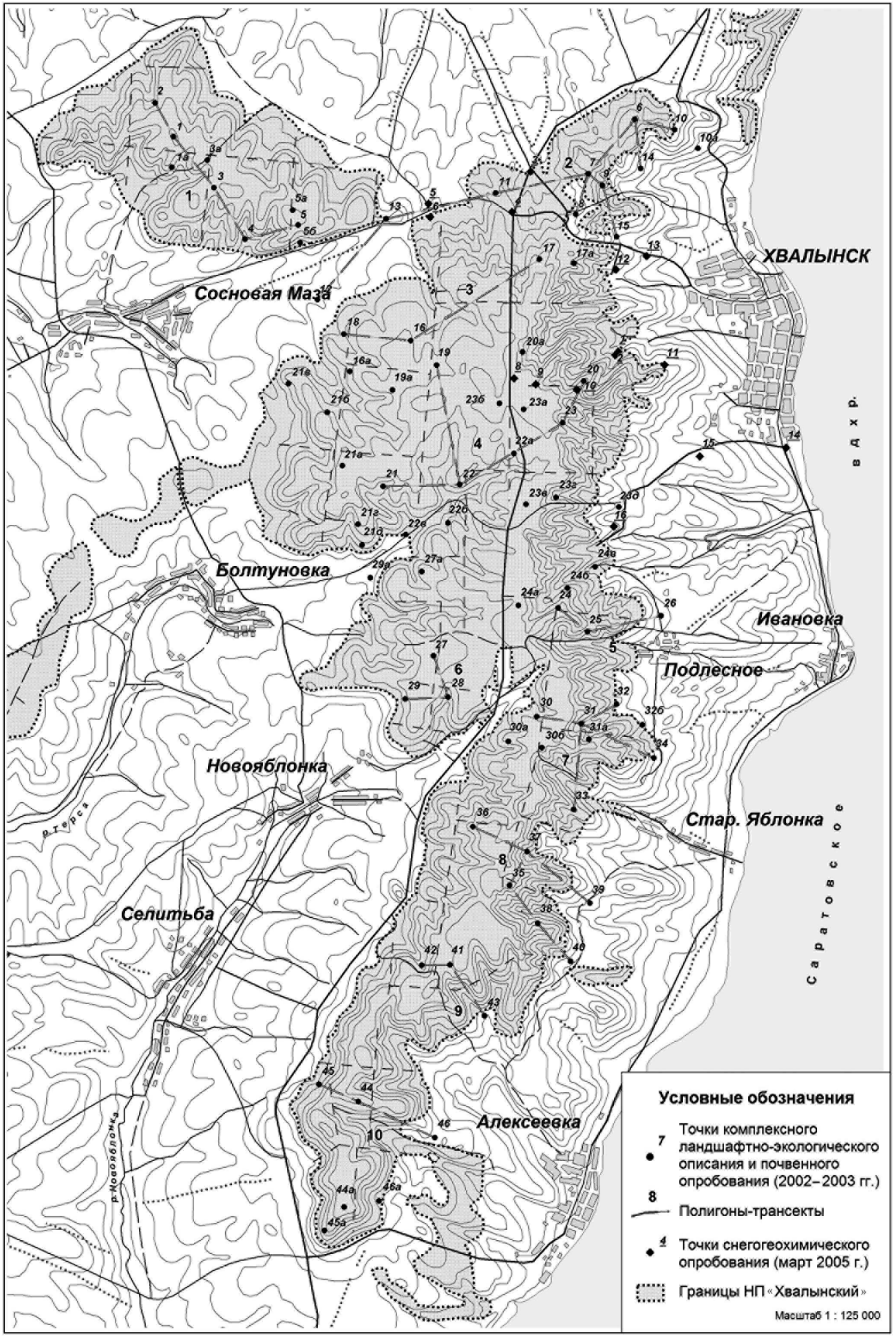

Модельные площадки и полигоны-трансекты ландшафтно-экологических исследований центральной части НП «Хвалынский» 
В результате были созданы разнообразные полевые карты: карты активных экзодинамических процессов, карты участков интенсивных вырубок в разной стадии зарастания, карта модельных площадок и обширная база полевых бланков (более 100), заполненных по единому образцу.

Полученный полевой материал переносился в электронные базы данных создаваемой природоохранной геоинформационной системы (ГИС) НП «Хвалынский».

В процессе полевых работ и последующей обработки полевых материалов уточнялось и дешифрировалось содержание космоснимка, производился химический анализ почвенных и водных проб.

На основе гипсометрической карты и данных микроклиматических наблюдений составлена карта суммарной радиации на модельных площадках в разных типах урочищ. Выполнено дешифрирование космического снимка территории Парка.

В марте 2005 г. была проведена первая снегогеохимическая съемка центрального участка Парка.

\section{Некоторые результаты полевых исследований за 2002-2005 годы}

\section{Результаты педохимических работ}

Как отмечалось выше, в 2002-2003 гг. в составе комплексных ландшафтно-экологических исследований были выполнены почвенные изыскания. На 81 модельной площадке были заложены почвенные шурфы с их морфологическим описанием и отбором почвенных образцов из различных генетических горизонтов.

Микроэлементный состав почвенных проб, отобранных с глубины 5-10 см (горизонт А), будет рассмотрен ниже.

Почвенные образцы были подготовлены для приближенно-количественного спектрального анализа. Спектральный анализ выполнялся на спектрографе ИСП-28 в лаборатории геологического отдела Института естественных наук Саратовского государственного университета (зав. лаб. 3.А. Яночкина).

Приближенно-количественный спектральный анализ проб отвечает всем требованиям, предъявляемым к аналитическим исследованиям по выявлению общей загрязненности территории тяжелыми металлами. В рамках регионального мониторинга эколого-геохимической ситуации в России ежегодно выполняются миллионы элементо-определений тяжелых металлов. Примерно 95\% проб анализируются методом приближенно-количественного спектрального анализа.

Данный метод отличает экспрессность и относительная дешевизна, широкий набор определяемых микроэлементов-загрязнителей, достаточная чувствительность и хорошая воспроизводимость.
После выполнения спектрального анализа была осуществлена математико-статистическая обработка полученных результатов, определена стандартная ошибка метода и отбракованы случайные показатели.

Затем в специализированной, созданной в Московском государственном университете, программе MAG были подготовлены математикокартографические модели концентраций наиболее экотоксичных элементов в подвижной форме. К ним были отнесены соединения свинца, хрома, никеля, меди, цинка.

Кроме того, было определено общее валовое содержание в почве марганца и ванадия.

Анализ карт содержания в почве указанных микроэлементов позволил выявить следующие педохимические особенности территории Парка и буферной зоны:

1. По всем рассматриваемым микроэлементам концентрации подвижных и нерастворимых форм не достигают и половины ПДК. Таким образом, с санитарно- гигиенической точки зрения территория Хвалынского национального парка во всех функциональных зонах и на буферной территории является относительно чистой, относящейся к первому, допустимому уровню загрязнения почвы тяжелыми металлами.

2. Обнаружена определенная вариабельность в содержании микроэлементов в верхнем горизонте почвы. Выяснилась педохимическая очаговая неоднородность территории, которая различна для разных химических элементов.

3. Относительно повышенных концентраций обнаружены следующие химические ореолы:

- свинца - на севере территории Парка на приводораздельных склонах юго-восточной экспозиции, на вырубках и в мелколиственных лесах недалеко от шоссейной дороги, идущей из Хвалынска на главное шоссе Саратов - Сызрань. Повышенное содержание свинца можно объяснить наличием сети шоссейных дорог в пригородной зоне и относительно оживленным движением в районе Хвалынска и магистрального шоссе;

- положительные геохимические аномалии хрома отмечены в северной части территории и локально вдоль трассы Саратов - Сызрань, что также может быть объяснено движением транспорта по автомагистрали;

- повышенные концентрации подвижных форм никеля выявлены в северной, центральной и южной частях обследованной территории. Все они, как правило, приурочены к автотрассе Саратов - Сызрань и шоссе, соединяющему Хвалынск с главной автомагистралью, что, так же как и в предыдущих случаях, предполагает влияние автотранспорта;

- положительные, относительно среднего содержания, аномалии концентрации меди обнаружены на участках, прилегающих к автомагистралям. Наиболее крупный ореол расположен в 
северной части территории с наибольшей плотностью автодорог;

- распределение повышенных концентраций цинка также соответствует выявленным ранее закономерностям - вдоль шоссе, пятнами - в северной, центральной и южной частях территории;

- аномалии марганца территориально не соответствуют выявленным закономерностям в распределении других элементов, зато педохимические аномалии ванадия повторяют их - в основном вдоль автодорог и отдельными очагами-ореолами.

\section{Выводы по педохимическим исследованиям}

1. Геохимическая нагрузка тяжелых металлов на почвы в пределах Парка является допустимой и не превышает 0,5 ПДК по свинцу, хрому, никелю, меди, цинку, марганцу и ванадию.

2. Ореолы относительного увеличения содержания указанных химических элементов (кроме марганца) расположены вдоль автодорог и зависят от господствующих ветров и рельефа. Наиболее загрязненным следует признать северный пригородный участок Парка.

3. Основным фактором, вызывающим загрязнение почвы тяжелыми металлами, является движение автотранспорта и, следовательно, оживленные автодороги, проложенные по территории Хвалынского национального парка.

\section{Результаты снеговой съемки}

Снегогеохимическая съемка была впервые выполнена на территории центрального участка Хвалынского национального парка и в буферной зоне 23-25 марта 2005 г. В.3. Макаровым, Ю.В. Волковым и В.А. Даниловым. Участниками съемки были пройдены лыжные и пешеходные маршруты во всех функциональных зонах парка: лесохозяйственной, рекреационной и заповедной. Изучались высота, структура и плотность снегового покрова в лесах и на вырубках, на лесных полянах, на степных безлесных участках, в садовых плантациях, в населенных пунктах. Снегомерные работы выполнялись на модельных участках и профилях (полигонах-трансектах), расположенных в различных ландшафтных выделах: Западном макросклоне, Главном водоразделе Хвалынских гор, Восточном макросклоне, в балках-ущельях, котловинах-польях, на волжских террасах. В процессе исследований обнаружилась важная роль направлений метелевого переноса, леса и кустарника как механических барьеров на пути движения воздуха, экспозиции и крутизны склонов, интенсивности солнечной радиации, испарения снега на открытых участках. Эти и ряд других факторов ощутимо влияют на пространственную дифференциацию в распределении снежного покрова на территории Парка. Выявлена значительная мощность снежного покрова в лесах на водоразделах и склоновом мелколесье, а также в тальвегах балок. Здесь высота снега колеблется от 85 до 124 и более сантиметров. На модельных участках были отобраны снежные пробы для последующего геохимического анализа, определены влагозапасы в снежном покрове. Полученные данные входят в базы данных ГИС НП «Хвалынский». Попытка определить геохимический состав твердой (пылевой) и растворенной фракции аэрозолей и твердых частиц в снеговой воде не дала результатов из-за малого количества выпадений в отобранных снеговых пробах.

\section{Результаты биоценологических наблюдений}

Маршрутные и полустационарные исследования структуры и состава фитоценозов в различных функциональных зонах Парка позволяют высказать ряд замечаний относительно современного состояния биоценотического покрова центральной части территории Парка.

1. Западная часть территории Парка, включающая водораздельные и склоновые урочища Западного макросклона и Главного водораздельного массива, несет следы былых сплошных вырубок дубовых лесов, продолжавшихся на протяжении по меньшей мере последних 80 лет. Особенно отчетливы следы вырубок вдоль федеральной автодороги Саратов - Сызрань и по дороге на с. Сосновая Маза.

2. Господствующими древесными породами в Парке являются низкоствольный дуб, липа, клен остролистный, осина и береза. Дуб в массе своей низкого бонитета ( III в и ниже), часто поражен корневой гнилью и суховершинностью. Все дубравы не семенные, а порослевые, как, впрочем, везде в Саратовской области.

3. Главная природно-историческая ценность древесной растительности Парка - так называемая сосна меловая - сохранилась в восточной части Парка на главном уступе Хвалынских гор, там, где рельеф сильно расчленен, склоны покатые и крутые. Доля естественных сосновых насаждений в составе лесов Парка незначительна - не более $15 \%$.

4. Наиболее привлекательными в рекреационном отношении являются уступ Восточного макросклона и более пологие его склоны, выходящие к Волге и расчленные балками-ущельями. Здесь наибольшее разнообразие растений, наличие панорамных точек.

5. Повышение рекреационной привлекательности водораздельных урочищ, расположенных вдоль федерального шоссе, требует проведения работ по ландшафтному дизайну.

\section{Общие выводы}

Главное направление ландшафтно-экологических работ в Хвалынском национальном парке связано с созданием учебно-научной базы-стационара на его территории. Учебно-научный стацио- 
нар Саратовского государственного университета будет создан на месте бывшего пионерлагеря «Лесная поляна».

Научные полустационарные и стационарные исследования будут направлены на решение следующих задач:

1. Инвентаризацию и оценку природно-ресурсного и рекреационного потенциала ландшафтно-экологических систем ранга урочище - водосборный бассейн 4-5-го порядков - местность.

2. Разработку и внедрение системы ландшафтно-экологического мониторинга на территории Парка и буферной зоны.

3. Организацию натурных и дистанционных мониторинговых сезонных наблюдений за состоянием геоэкосистем на модельных полигонахтрансектах и всей территории Парка.

4. Оценку уровней допустимых рекреационных и хозяйственных нагрузок в различных видах и типах биогеосистем на основе данных натуральных наблюдений и имитационного моделирования.

5. Создание природоохранной геоинформационной системы НП «Хвалынский».
6. Обсуждение с коллегами и общественностью научных результатов, полученных путем публикаций и организации семинаров и конференций.

Таким образом, есть уверенность, что в работе Хвалынского национального парка появится надежная научная основа.

\section{Библиографический список}

1. Макаров В.З., Данилов В.А. Волжская «Швейцария»Хвалынский национальный парк: природные особенности и проблемы развития // Развитие физической географии и ландшафтной экологии в Саратовском университете: Сб. науч. тр. / Под ред. д-ра геогр. наук, проф. В.З. Макарова. Саратов, 2005. С. 85-93.

2. Технико-экономическое обоснование организации Национального природного парка «Хвалынский» Саратовской области: В 2 т. Саратов, 1995. Т. 1. Объяснительная записка. Раздел «Организация развития лесного хозяйства НП «Хвалынский». $250 \mathrm{c}$.

3. Анненская Г.Н., Видина А.А., Жучкова В.К. и др. Морфологическое изучение географических ландшафтов // Ландшафтоведение. М., 1963. С. 5-28.

4. Программа и методика биогеоценологических исследований. М., 1974. 237 с.



УДК 551.50 .63

\section{ВЛИЯНИЕ ВЕСЕННИХ ЗАПАСОВ ПРОДУКТИВНОЙ ВЛАГИ В ПОЧВЕ И ОСАДКОВ НА ПРОДУКТИВНОСТЬ ЗЕРНОВЫХ КУЛЬТУР В ЗОНЕ ЗАСУШЛИВОЙ ЧЕРНОЗЕМНОЙ СТЕПИ}

\section{Ю.Ф. Курдюков ${ }^{1}$, М.Ю. Васильева, С.И. Пряхина}

\author{
Саратовский государственный университет, \\ кафедра метеорологии и климатологии \\ E-mail:kafmeteo@sgu.ru \\ ${ }^{1}$ НИИ СХ Юго-Востока, отдел земледелия и агротехники \\ E-mail:raiser@mail.saratov.ru
}

Анализ многолетних данных позволил установить корреляционную зависимость между урожайностью зерновых культур, весенними запасами продуктивной влаги в почве и количеством осадков в отдельные периоды их роста и развития.

Influence of Spring Provision of Productive Moisture in Soil and Precipitation on Cereal's Crop Productivity in Arid Black Earth Steppe

\section{Yu.F. Kurdiukov, M.Yu. Vasilieva, S.I. Pryakhina}

Analysis of many years' data lets to determine correlation of the cereal's crop capacity with spring provision of productive moisture in soil and the precipitations quantity in different periods of the cereal's growth and development.

Засушливая черноземная степь Саратовского Правобережья расположена в пределах Чардымо-
Курдюмского, Волго-Карамышского и ИдолгоКолышлейского физико-географических районов восточного склона Приволжской возвышенности и занимает промежуточное положение между лесостепной и сухостепной зонами.

Термический режим территории не лимитирует рост и развитие зерновых культур. Определяющее значение в формировании их продуктивности имеют атмосферные осадки, обеспечивающие создание запасов почвенной влаги и условия влагообеспеченности в период вегетации.

Проведенные исследования показали, что за последние 34 года в зоне засушливой черноземной степи гидротермический режим в 39\% лет складывался по типу, характерному для лесостепной зоны (осадки более 500 мм), а в 24\% лет - по типу сухой степи (осадки менее 390 мм). Большая изменчивость годовых сумм осадков приводит к неустойчивому увлажнению территории и дестабилизации в отдельные годы сельскохозяйственного производства.

Цель данной работы - анализ зависимости урожая зерновых культур от весенних запасов продуктивной влаги (ЗПВ) в метровом слое поч- 